\title{
Protocol for a randomized clinical trial: telephone-based psychoeducation and support for female informal caregivers of patients with dementia
}

\author{
Protocolo para ensaio clínico randomizado: psicoeducação por telefone e \\ apoio para cuidadoras informais femininas de pacientes com demência
}

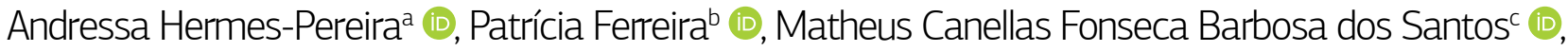 \\ Pedro Alves Fagundes ${ }^{c}(\mathbb{0})$, Ana Paula Bresolin Gonçalves ${ }^{b}$ (1), Dimitris Varvaki Rados ${ }^{d}(\mathbb{D}$, \\ Raphael Machado Castilhos ${ }^{e}\left(\mathbb{D}\right.$, Lucas Porcello Schilling ${ }^{b}$ (1) Márcia Lorena Fagundes Chaves ${ }^{f}$ (D),

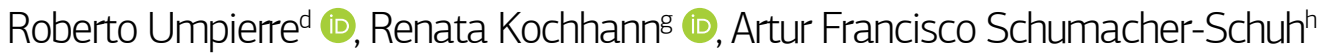

\begin{abstract}
OBJECTIVE: The burden felt by informal caregivers of patients with dementia is a source of physical, emotional, and financial problems. Face-to-face interventions for caregivers have accessibility limitations that may prevent them from receiving adequate care. Telehealth tools can be a solution to this problem. We will compare a telephone psychoeducational and support intervention protocol to usual care for informal female caregivers of patients with dementia treated at Brazilian specialized outpatient clinics. METHODS: In this single-blind randomized clinical trial, the intervention group will receive one weekly call for 8 weeks that addresses issues such as disease education, communication with the patient, and problematic behaviors. The control group will receive printed material on problematic behaviors in dementia. The primary outcome will be the difference in caregiver burden between baseline and 8 weeks, which will be assessed by blinded investigators through the Zarit Burden Interview scale. Caregiver burden at 16 weeks after baseline, depression, anxiety, and quality of life at 8 and 16 weeks are secondary outcomes. CONCLUSIONS: We expect the intervention to reduce caregiver burden. These results could lead to public health programs for improving dementia care in lower-middle-income countries. Ethics and dissemination: This trial was approved by an independent ethics committee. The results will be published in an international peer-reviewed medical journal. Trial registration number: NCT03260608.
\end{abstract}

KEYWORDS: dementia; caregiver; burden; telemedicine.

\footnotetext{
aFaculdade de Medicina, Universidade Federal do Rio Grande do Sul - Porto Alegre (RS), Brazil.

'Hospital São Lucas, Pontifícia Universidade Católica do Rio Grande do Sul - Porto Alegre (RS), Brazil.

Instituto de Psicologia, Universidade Federal do Rio Grande do Sul - Porto Alegre (RS), Brazil.

'Telessaúde RS, Universidade Federal do Rio Grande do Sul - Porto Alegre (RS), Brazil.

eServiço de Neurologia, Hospital Nossa Senhora da Conceição - Porto Alegre (RS), Brazil.

fServiço de Neurologia, Hospital de Clínicas de Porto Alegre - Porto Alegre (RS), Brasil.

sHospital Moinhos de Ventos - Porto Alegre (RS), Brasil.

"Departamento de Farmacologia, Universidade Federal do Rio Grande do Sul - Porto Alegre (RS), Brasil.

Address for correspondence

Andressa Hermes-Pereira - Rua Ramiro Barcelos, 2350 - Santa Cecília - CEP: 90035903 - Porto Alegre (RS), Brasil. E-mail: andressahpereira@gmail.com Received on: 09/13/2021. Accepted on: 11/01/2021

How to cite this article: Hermes-Pereira A, Ferreira P, Santos MCFB, Fagundes PA, Gonçalves APB, Rados DV, et al. Protocol for a randomized clinical trial: telephone-based psychoeducation and support for female informal caregivers of patients with dementia. Geriatr Gerontol Aging. 2021;15:e0210045. https://doi.org/10.53886/gga.e0210045 https://doi.org/10.53886/gga.e0210045
} 
OBJETIVO: A sobrecarga sentida por cuidadores informais de pacientes com demência é uma fonte de problemas físicos, emocionais e financeiros. As intervenções face a face para cuidadores apresentam limitações de acessibilidade que podem impedilos de receber cuidados adequados. As ferramentas de telessaúde podem ser uma solução para esse problema. Comparamos um protocolo de intervenção psicoeducacional e de apoio por telefone ao tratamento usual para cuidadoras informais de pacientes com demência tratados em ambulatórios especializados. METODOLOGIA: Será realizado um ensaio clínico randomizado simples-cego. Durante 8 semanas, o grupo de intervenção receberá uma ligação semanal abordando questões como educação sobre a doença, comunicação com o paciente e comportamentos problemáticos. O grupo controle receberá material impresso sobre comportamentos problemáticos na demência. O resultado primário será a diferença na sobrecarga da cuidadora entre o ponto de partida e oito semanas, que será avaliada por pesquisadores cegos com a escala Zarit Burden Interview. Sobrecarga da cuidadora em dezesseis semanas após o início do estudo, depressão, ansiedade e qualidade de vida após oito e dezesseis semanas são resultados secundários. CONCLUSÕES: Esperamos que a intervenção reduza a sobrecarga da cuidadora. Esses resultados podem levar a programas de saúde pública para melhorar o tratamento da demência em países de renda médiabaixa. Ética e divulgação: Este estudo foi aprovado por um comitê de ética independente. Os resultados serão publicados em uma revista médica internacional revisada por pares. Número de registro do teste: NCT03260608.

PALAVRAS CHAVE: demência; cuidadora; sobrecarga; telemedicina.

\section{INTRODUCTION}

Dementia is one of the foremost causes of disability and dependency among older adults, leading to a need for constant care. ${ }^{1}$ It engenders significant suffering for both patients and their caregivers, especially those who are family members. ${ }^{2,3}$ Two-thirds of individuals with dementia live in a lower-middle-income countries (LMIC), and Brazil has one of the highest estimated prevalences of dementia. ${ }^{4}, 1$ While in high-income countries the prevalence of dementia is tending to decrease, a fourfold increase is expected in Latin America by 2050 due to increased life expectancy, low education levels, and lower control of other risk factors. ${ }^{2,5}$ Despite this challenging scenario, the majority of intervention studies have been conducted in high-income countries and their results may not apply to the LMIC context.

Informal caregivers are unpaid family members, friends or acquaintances who take care of these patients, regularly spending time them. ${ }^{6}$ Caring for dementia patients demands great personal involvement and involves challenging situations. As a result, informal caregivers are susceptible to experience burden: a subjective multidimensional term that represents the physical, psychological, social, and financial impacts of the interaction between the caregiver's resources and vulnerabilities and the patient's demands. ${ }^{7-9}$ Increased caregiver burden is also associated with an increased risk of patient institutionalization. ${ }^{10}$

Psychoeducational interventions with caregivers decrease adverse symptoms, increase quality of life, and delay the permanent institutionalization of patients. ${ }^{11-13}$ However, faceto-face interventions face difficult barriers, such as transportation, residence in rural areas, the caregiving schedule, and the social stigma associated with seeking help. ${ }^{14}$ On the other hand, such barriers do not affect telephone interventions, and they have been used successfully to improve functionality in individuals with a variety of clinical problems. ${ }^{15,16}$ This strategy could be a more accessible, inexpensive, and efficient alternative.

This report presents the protocol for a randomized clinical trial to evaluate, in comparison with usual care, the efficacy of a telephone-based psychoeducation and support intervention to reduce the burden of informal female caregivers of patients with dementia who are followed in specialized outpatient clinics in Brazil. The primary outcome will be caregiver burden and the secondary outcomes will be caregiver anxiety, depression, and quality of life, and patient functionality. We hypothesize that our intervention will decrease caregiver burden, which can widen strengthen the health system's efficiency in dementia and old-age care.

\section{METHODS}

\section{Study design}

This will be a single-blind parallel randomized controlled trial. Due to the nature of the intervention, caregiver blinding will not be feasible. The researchers who perform the evaluations will be blinded.

Study setting

Recruitment is ongoing in three university outpatient memory clinics in Porto Alegre, Brazil. 


\section{Study sample}

The sample will consist of female family caregivers of patients with dementia. The diagnosis of dementia will have been previously checked in the patients' medical records.

Inclusion criteria:

1. caregivers of patients with dementia of any etiology and severity,

2. female family member of the patient,

3. informal caregivers (unpaid),

4. responsibility for the patient for at least 40 hours per week for a minimum of 6 months, and

5. at least 4 years of formal education.

Exclusion criteria:

1. physical limitations that prevent applying research instruments,

2. caregivers of patients with significant functional impairment related to other diseases rather than dementia, and

3. planning to transfer the patient to an assisted living facility within 6 months.

\section{Randomization}

The randomization list will be computer generated in blocks of 4 and 6 , and the allocation sequence will be stored in sealed opaque envelopes. An external investigator will conduct the randomization. Only investigators responsible for the intervention will be informed about group allocation (Figure 1). The statistical analysis team will be blinded to group randomization.

\section{Outcomes}

Blinded researchers will conduct three assessments: baseline, 8 weeks later (post-intervention), and 16 weeks later (follow-up). The primary outcome will be the difference in mean Zarit Burden Interview scores between baseline and 8 weeks. Secondary outcomes will be the difference in mean Zarit Burden Interview scores between baseline and 16 weeks and between 8 and 16 weeks, and caregiver anxiety, depression, and quality of life, in addition to patient neuropsychiatric and functional impairment. Table 1 summarizes outcome measures. Safety and satisfaction with the intervention will also be investigated with open-ended questions and a request for feedback.

\section{Instruments}

1. Zarit Burden Interview: ${ }^{16,17}$ a structured interview consisting of 22 questions, aimed at assessing caregiver burden;
2. Beck Depression Inventory-II): ${ }^{18}$ detects and measures the severity of depressive symptoms;

3. Beck Anxiety Inventory: ${ }^{19}$ detects and measures the severity of anxiety symptoms;

4. World Health Organization Quality of Life Questionnaire: ${ }^{20}$ self-assessment scale that encompasses 4 quality of life domains (psychological, physical health, social relations, and the environment)

5. Neuropsychiatric Inventory Questionnaire: ${ }^{21,22}$ assesses the presence and severity of the patient's neuropsychiatric symptoms through a questionnaire answered by the caregiver;

6. Pfeffer Functional Activities Questionnaire: ${ }^{23,24}$ evaluates 10 instrumental activities of daily living in relation to different cognitive skills.

\section{Intervention}

Caregivers in the intervention group will receive eight weekly phone calls, each lasting approximately 30 minutes. If we are unable to reach the caregiver on the appointed week, three more contact attempts will be made during that week. On the following week, we will try to make contact again. The calls will be carried out by undergraduate psychology students who have been trained in a standardized psychoeducation and support protocol aimed at caregivers of dementia patients. To maintain protocol fidelity throughout the study period, biweekly meetings will be held to supervise the intervention team.

The first call will discuss how the program functions, provide education about the disease (reviewed on the fifth call), and discuss communication with the patient (reviewed on the sixth call). The second call will address problematic behaviors in the patient. The third call will be about caring for caregivers themselves (reviewed on the seventh call). The fourth call will discuss modifying the environment (reviewed on the eighth call). The other four calls will focus on problematic behavior and review previously discussed topics.

The frequency of problematic behavior will be addressed through five steps aimed at identifying and preventively modifying triggering stimuli, as well as the environmental consequences of the behavior ${ }^{25}$. The instructions given to caregivers will be:

1. Describe the problem in detail,

2. Identify triggers or situations in which the problem occurs,

3. Describe your reactions to the behavior or what happens right after the patient behaves that way,

4. Think about what can be changed in your attitude or the environment to eliminate triggers, 


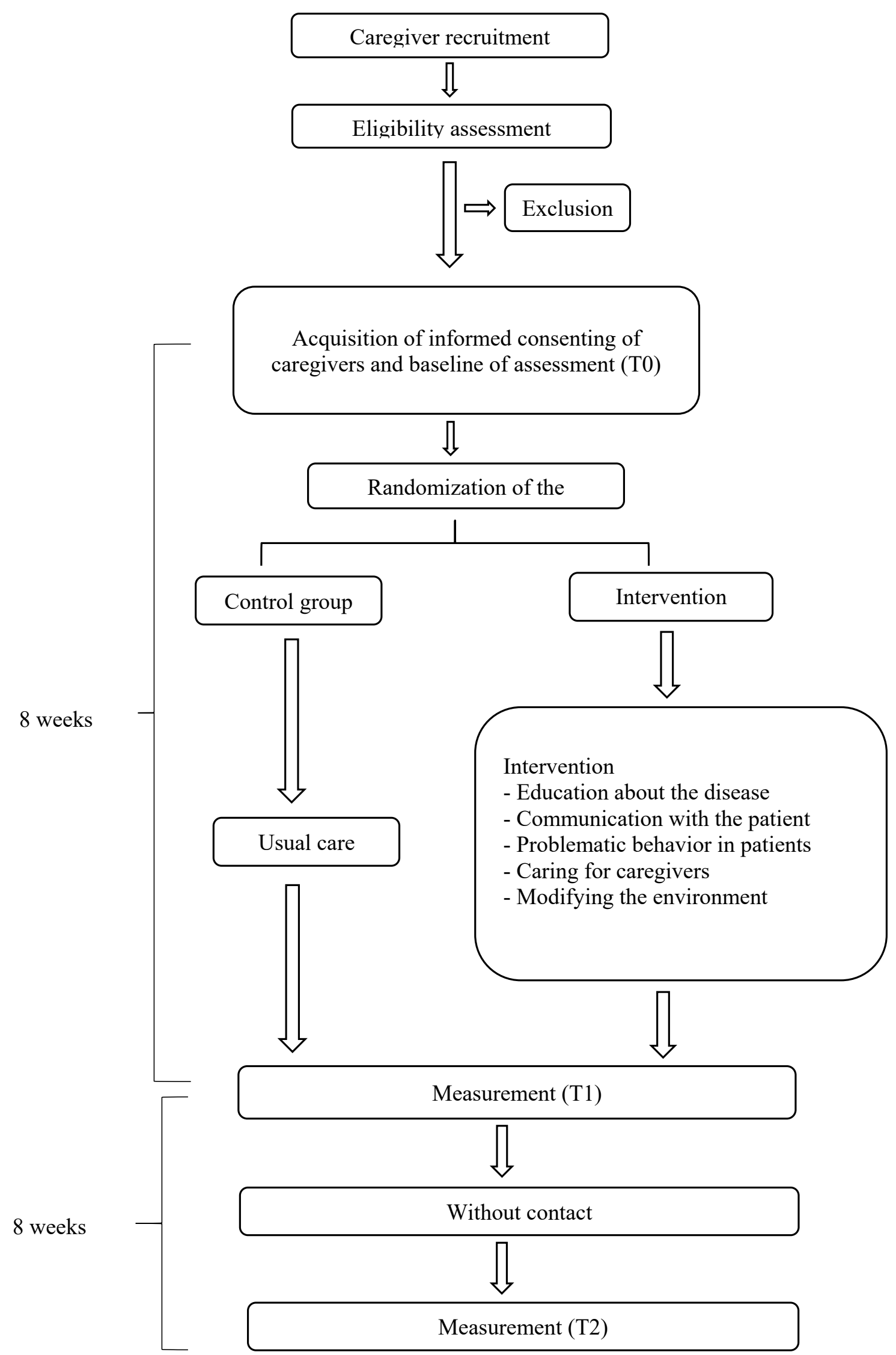

Figure 1. Flowchart of the enrollment process for this randomized controlled trial. 
Table 1. Characteristics of the measurement instruments.

\begin{tabular}{l|c|c|c}
\hline Instruments & Minimum - Maximum & Measurement & Type of Variable \\
\hline Zarit Burden Interview ${ }^{16}$ & $0-88$ & $\mathrm{~T}_{0-} \mathrm{T}_{1-} \mathrm{T}_{2}$ & Primary Outcome \\
\hline Beck Depression Inventory-II $^{18}$ & $0-63 \mathrm{~T}$ & $\mathrm{~T}_{0-} \mathrm{T}_{1-} \mathrm{T}_{2}$ & Secondary outcome \\
\hline Beck Anxiety Inventory $^{19}$ & $0-63$ & $\mathrm{~T}_{0-} \mathrm{T}_{1-} \mathrm{T}_{2}$ & Secondary outcome \\
\hline WHO Quality of Life Questionnaire $^{20}$ & $1-5$ & $\mathrm{~T}_{0-} \mathrm{T}_{1-} \mathrm{T}_{2}$ & Secondary outcome \\
\hline Neuropsychiatric Inventory-Questionnaire $^{21}$ & $\begin{array}{c}\text { Severity } 1-36 \\
\text { Care distress 0-60 }\end{array}$ & $\mathrm{T}_{0-} \mathrm{T}_{1-} \mathrm{T}_{2}$ & Secondary outcome \\
\hline Pfeiffer Functional Activities Questionnaire $^{24}$ & $0-30$ & $\mathrm{~T}_{0-} \mathrm{T}_{1-} \mathrm{T}_{2}$ & Secondary outcome \\
\hline
\end{tabular}

5. Think about alternative ways of handling the problem that could modify the outcome.

Caregivers will be able to send text messages if they have questions or problem situations between intervention phone calls, which will be answered in up to 48 hours. If the caregiver has questions about medications, laboratory exams, other medical conditions, or other subjects beyond the scope of the intervention, they will be directed to their local health service.

When certain common dementia-related behaviors are identified (hallucinations, delirium, agitation, irritability, repeating questions, hiding objects, walking uninterruptedly, aggression, anxiety, apathy, social or sexual disinhibition, sleep problems, suspicion, depression, refusing care, and caregiver feelings of guilt), specific directions will be given about how to handle them. In addition, the interventionists will help caregivers develop their own answers to their problems, generalizing their knowledge and developing independence from the protocol. Some specific interventions such as validation, positive reframing, and normalization will be performed as necessary.

\section{Control group}

Caregivers in the control group will receive an explanatory brochure about handling difficult situations with dementia patients. This material will contain guidelines on how to deal with common behaviors in patients with dementia, such as sleep problems, bathing problems, and aggression (Figure 2).

\section{Statistical analysis}

The primary outcome will be analyzed with a generalized estimating equation model using a modified intentionto-treat principle, which includes all caregivers who receive at least one intervention (one phone call). Secondary outcomes will be assessed through this same intention-to-treat or per-protocol principle. All analysis will be performed using
$\mathrm{R}$ software, and a two-sided significance level of $5 \%$ will be considered. All missing data will be deleted from the analysis.

\section{Sample size calculation}

The sample size was calculated to detect a $46 \%$ reduction in mean Zarit Burden Interview scores based on Kwok et al. ${ }^{26} \mathrm{An} 80 \%$ statistical power and a 0.05 significance level were considered. Within these parameters, a sample size of 74 subjects was calculated for each group.

\section{Ethics and dissemination}

This trial will be conducted in accordance with the Declaration of Helsinki and has been approved by the Hospital de Clínicas de Porto Alegre ethics committee (approval number 2017-0326). All participants will provide written informed consent. The results will be presented in research meetings and will be published in a peer-reviewed journal.

\section{EXPECTED RESULTS}

Caregiver burden is defined as the degree to which a caregiver's emotional or physical health, social life, or financial status has suffered as a result of caring for their relative. ${ }^{27}$ It is quite common among dementia caregivers: ${ }^{28}$ a study found that $85.6 \%$ of dementia caregivers consider themselves to be suffering from caregiver burden, with $66.3 \%$ reporting an intense burden. ${ }^{29}$ Caregiver burden increases commensurately with disease progression, involving greater depression, the development of psychiatric symptoms, and lower quality of life among caregivers, as well as a greater frequency of nursing home placement. ${ }^{30,31}$

In this trial the primary outcome will be the results of Brazilian version of the Zarit Burden Interview, ${ }^{16}$ which is one of the most commonly used scales for assessing caregiver burden. ${ }^{32,33}$ This instrument measures burden as a multifactorial construct. ${ }^{34}$ 
Gradual loss of functionality is a core symptom of dementia. The patient's increasing functional impairment seems even more relevant to caregiver burden than disease-related cognitive-behavioral changes. ${ }^{35}$ We will use the Pfeffer Functional Activities Questionnaire, which is widely used to assess functionality in dementia patients. ${ }^{24}$

Our protocol focuses on informal, i.e., unpaid, caregivers who are women, i.e., the majority of caregivers, especially in lower middle-income countries. ${ }^{36}$ Women more often provide personal and instrumental care than men and also have higher levels of caregiver burden and depression. ${ }^{37}$ Moreover, they are more likely to benefit from caregiver interventions. ${ }^{32}$

Our multicomponent and individualized intervention will focus primarily on psychoeducation support. Caregivers will be taught to find solutions for their own problems, actively participating in the process. A meta-analysis found that

\section{Compreendendo comportamentos difíceis.}

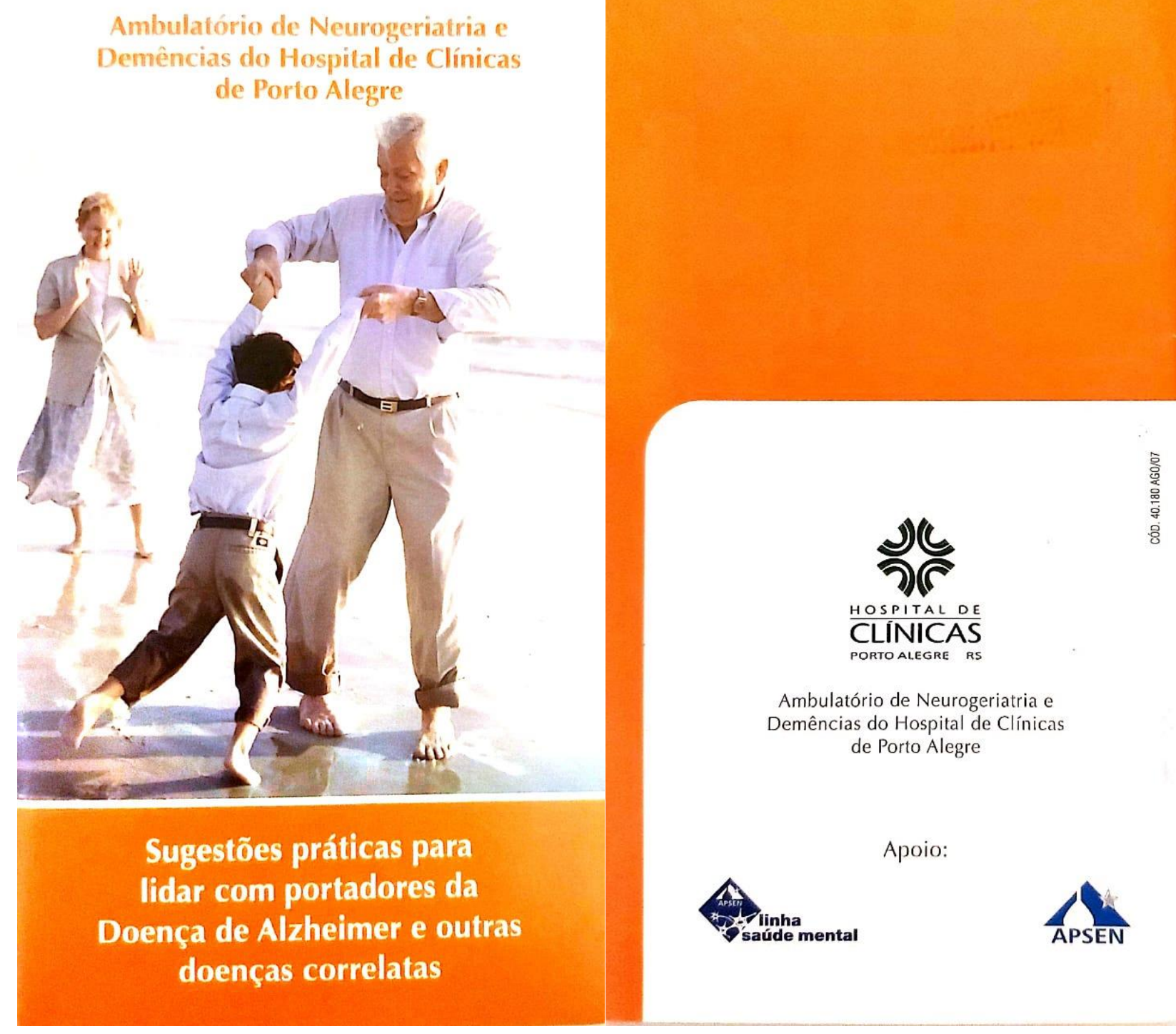

Understanding difficult behaviors

Hospital de Clínicas de Porto Alegre Neurogeriatric and Dementia Clinic

Practical suggestions for dealing with patients with Alzheimer's and other related diseases

Figure 2. Brochure on handling difficult situations. 
psychoeducational interventions in which caregivers actively participated achieved the broadest effects of all intervention types. ${ }^{32}$ On the other hand, interventions that merely provide information and limited time for discussion seem insufficient to reduce stressors, caregiver burden, and depressive symptoms.

In addition, structured multicomponent interventions, such as a combination of education and support interventions, have been found to be the only type that decreases the risk of institutionalization while also reducing caregiver burden and depressive symptoms and improving their general health and social support. ${ }^{38}$ However, the lack of randomization and control groups in most intervention studies limit conclusions about their effects. ${ }^{14}$

Technology-based programs have recently been developed to overcome the logistical problems of in-person interventions for caregivers of older dementia patients. ${ }^{39,40}$ The results have shown that caregivers can receive emotional support, information about the disease, and find relief from emotional symptoms through the Internet and telecommunications. It has been found that telephone interventions effectively reduce depressive symptoms. ${ }^{38}$ However, to the best of our knowledge, there is no evidence about caregiver burden as the primary outcome of an individual technology-based intervention in a LMIC from a robustly designed, randomized trial with a control group.

\section{RELEVANCE AND DISSEMINATION}

Dementia poses significant health and economic challenges worldwide, but especially in LMIC, where the majority of people with dementia live and where its incidence is expected to rise. It is essential to conduct well-designed intervention trials to face this challenge and support both clinical and public health decisions. Interventions aimed at reducing caregiver burden could be an important tool for reducing dementia care costs and adverse health consequences. ${ }^{36}$ In Brazil, a country of great size and great economic inequality, the use of a telehealth tool, as proposed in this protocol, can be an accessible, effective, and inexpensive way to improve caregiver burden. The results of this study could lead to public health programs to improve dementia care in LMIC.

\section{CONFLICTS OF INTEREST}

The authors declare no conflicts of interest

\section{FUNDING}

This study received no specific grants from funding agencies in the public, commercial, or not-for-profit sectors.

\section{AUTHOR CONTRIBUTIONS}

AHP: Conceptualization, writing - original draft, writing - review \& editing. PF: Writing - original draft. MCFBS: Writing - original draft. PAF: Writing - original draft. APBG: Writing - original draft. DVR: Conceptualization, writing - original draft, writing - review \& editing. RMC: Conceptualization. LPS: Conceptualization, writing - review \&editing. MLFC: Conceptualization. RU: Conceptualization, writing - review \& editing. RK: Conceptualization, writing - original draft, writing - review \& editing. AFSS: Conceptualization, data curation, formal analysis, writing - review \& editing.

\section{REFERENCES}

1. Tisher A, Salardini A. A comprehensive update on treatment of dementia. Semin Neurol. 2019;39(2):167-78. https://doi. org/10.1055/s-0039-1683408

2. Livingston G, Sommerlad A, Orgeta V, Costafreda SG, Huntley J, Ames D, et al. Dementia prevention, intervention, and care. Lancet. 2017;390(10113):2673-734. https://doi.org/10.1016/S01406736(17)31363-6

3. Mavandadi S, Wright EM, Graydon MM, Oslin DW, Wray LO. A randomized pilot trial of a telephone-based collaborative care management program for caregivers of individuals with dementia. Psychol Serv. 2017;14(1):102-11. https://doi.org/10.1037/ser0000118

4. GBD 2016 Dementia Collaborators. Global, regional, and national burden of Alzheimer's disease and other dementias, 1990-2016: a systematic analysis for the Global Burden of Disease Study 2016. Lancet Neurol. 2019;18(1):88-106. https://doi.org/10.1016/S1474-4422(18)30403-4

5. Parra MA, Baez S, Allegri R, Nitrini R, Lopera F, Slachevsky A, et al. Dementia in Latin America: assessing the present and envisioning the future. Neurology. 2018;90(5):222-31. https://doi.org/10.1212/ WNL.0000000000004897

6. Cova I, Travi N, Maggiore L, Cucumo V, Mariani C, Pomati S. What are the caregivers' needs on dementia care? An integrated qualitative and quantitative assessment. Neurol Sci. 2018;39(6):1085-91. https://doi.org/10.1007/s10072-018-3332-3

7. Chiu M, Pauley T, Wesson V, Pushpakumar D, Sadavoy J. Evaluation of a problem-solving (PS) techniques-based intervention for informal carers of patients with dementia receiving in-home care. Int Psychogeriatr. 2015;27(6):937-48. https://doi.org/10.1017/S1041610214002798

8. Pendergrass A, Malnis C, Graf U, Engel S, Graessel E. Screening for caregivers at risk: Extended validation of the short version of the Burden Scale for Family Caregivers (BSFC-s) with a valid classification system for caregivers caring for an older person at home. BMC Health Serv Res. 2018;18(1):229. https://doi.org/10.1186/s12913-018-3047-4

9. Vitaliano PP, Young HM, Russo J. Burden: a review of measures used among caregivers of individuals with dementia. Gerontologist. 1991;31(1):67-75. https://doi.org/10.1093/geront/31.1.67 
10. Springate BA, Tremont G. Dimensions of caregiver burden in dementia: impact of demographic, mood, and care recipient variables. Am J Geriatr Psychiatry. 2014;22(3):294-300. https://doi.org/10.1016/j. jagp.2012.09.006

11. Cheng ST, Li KK, Losada A, Zhang F, Au A, Thompson LW, et al. The effectiveness of nonpharmacological interventions for informal dementia caregivers: an updated systematic review and metaanalysis. Psychol Aging. 2020;35(1):55-77. https://doi.org/10.1037/ pag0000401

12. Guerra M, Ferri CP, Fonseca M, Banerjee S, Prince M. Helping carers to care: the 10/66 dementia research group's randomized control trial of a caregiver intervention in Peru. Braz J Psychiatry. 201 1;33(1):4754. https://doi.org/10.1590/s1516-44462010005000017

13. Wolff JL, Rand-Giovannetti E, Palmer S, Wegener S, Reider L, Frey $\mathrm{K}$, et al. Caregiving and chronic care: the guided care program for families and friends. J Gerontol A Biol Sci Med Sci. 2009;64(7):78591. https://doi.org/10.1093/gerona/glp030

14. Tremont G, Davis JD, Papandonatos GD, Ott BR, Fortinsky RH, Gozalo $P$, et al. Psychosocial telephone intervention for dementia caregivers: a randomized, controlled trial. Alzheimers Dement. 2015;1 1(5):541-8. https://doi.org/10.1016/j.jalz.2014.05.1752

15. Berwig M, Heinrich S, Spahlholz J, Hallensleben N, Brähler E, Gertz HJ. Individualized support for informal caregivers of people with dementia - effectiveness of the German adaptation of REACH II. BMC Geriatr. 2017;17(1):286. https://doi.org/10.1186/s12877-017-0678-y

16. Scazufca M. Brazilian version of the Burden Interview scale for the assessment of burden of care in carers of people with mental illnesses. Braz J Psychiatry. 2002;24(1):12-7. https://doi.org/10.1590/ S1516-44462002000100006

17. Zarit SH, Zarit JM. The memory and behavior problems checklist1987R and the burden interview (technical report). Pennsylvania: Pennsylvania State University; 1987.

18. Beck AT, Steer RA, Brown G. BDI-II: Beck Depression Inventory manual. San Antonio: Psychological Corporation; 1996.

19. Beck AT, Epstein N, Brown G, Steer RA. An inventory for measuring clinical anxiety: psychometric properties. J Consult Clin Psychol. 1988;56(6):893-7. https://doi.org/10.1037//0022-006x.56.6.893

20. Development of the World Health Organization WHOQOL-BREF quality of life assessment. The WHOQOL Group. Psychol Med. 1998;28(3):551-8. https://doi.org/10.1017/s0033291798006667

21. Camozzato AL, Godinho C, Kochhann R, Massochini G, Chaves ML. Validity of the Brazilian version of the Neuropsychiatric Inventory Questionnaire (NPI-Q). Arq Neuropsiquiatr. 2015;73(1):41-5. https:// doi.org/10.1590/0004-282X20140177

22. Kaufer DI, Cummings JL, Ketchel P, Smith V, MacMillan A, Shelley T, et al. Validation of the NPI-Q, a brief clinical form of the Neuropsychiatric Inventory. J Neuropsychiatry Clin Neurosci. 2000;12(2):233-9. https:// doi.org/10.1176/jnp.12.2.233

23. Assis LO, Paula JJ, Assis MG, Moraes EN, Malloy-Diniz LF. Psychometric properties of the Brazilian version of Pfeffer's Functional Activities Questionnaire. Front Aging Neurosci. 2014;6:255. https://doi. org/10.3389/fnagi.2014.00255

24. Pfeffer RI, Kurosaki TT, Harrah Júnior CH, Chance JM, Filos S. Measurement of functional activities in older adults in the community. J Gerontol. 1982;37(3):323-9. https://doi.org/10.1093/geronj/37.3.323

25. Teri L, Huda P, Gibbons L, Young H, van Leynseele J. STAR: a dementia-specific training program for staff in assisted living residences. Gerontologist. 2005;45(5):686-93. https://doi.org/10.1093/ geront/45.5.686

26. Kwok T, Wong B, Ip I, Chui K, Young D, Ho F. Telephone-delivered psychoeducational intervention for Hong Kong Chinese dementia caregivers: a single-blinded randomized controlled trial. Clin Interv Aging. 2013;8:1191-7. https://doi.org/10.2147/CIA.S48264

27. Zarit SH, Todd PA, Zarit JM. Subjective burden of husbands and wives as caregivers: a longitudinal study. Gerontologist. 1986;26(3):260-6. https://doi.org/10.1093/geront/26.3.260

28. Chiao CY, Wu HS, Hsiao CY. Caregiver burden for informal caregivers of patients with dementia: a systematic review. Int Nurs Rev. 2015;62(3):340-50. https://doi.org/10.1111/inr.12194

29. Sequeira CAC. Adaptação e validação da Escala de Sobrecarga do Cuidador de Zarit. Referência. 2010;2(12):9-16.

30. Brodaty H, Woodward M, Boundy K, Ames D, Balshaw R, PRIME Study Group. Prevalence and predictors of burden in caregivers of people with dementia. Am J Geriatr Psychiatry. 2014;22(8):756-65. https://doi.org/10.1016/j.jagp.2013.05.004

31. Thyrian JR. People with dementia in primary care: Prevalence, incidence risk factors and interventions. Z Gerontol Geriatr. 2017;50(Suppl 2):32-8. https://doi.org/10.1007/s00391-017-1223-5

32. Pinquart M, Sörensen S. Helping caregivers of persons with dementia: which interventions work and how large are their effects? Int Psychogeriatr. 2006;18(4):577-95. https://doi.org/10.1017/ S1041610206003462

33. Yu J, Yap P, Liew TM. The optimal short version of the Zarit Burden Interview for dementia caregivers: diagnostic utility and externally validated cutoffs. Aging Ment Health. 2019;23(6):706-10. https:// doi.org/10.1080/13607863.2018.1450841

34. George LK, Gwyther LP. Caregiver well-being: a multidimensional examination of family caregivers of demented adults. Gerontologist. 1986;26(3):253-9. https://doi.org/10.1093/geront/26.3.253

35. Raccichini A, Castellani S, Civerchia P, Fioravanti P, Scarpino O. The caregiver's burden of Alzheimer patients: differences between live-in and non-live-in. Am J Alzheimers Dis Other Demen. 2009;24(5):37783. https://doi.org/10.1177/1533317509340025

36. Boots LM, Vugt ME, van Knippenberg RJ, Kempen GI, Verhey FR. A systematic review of Internet-based supportive interventions for caregivers of patients with dementia. Int J Geriatr Psychiatry. 2014:29(4):331-44. https://doi.org/10.1002/gps.4016

37. Pinquart M, Sörensen S. Gender differences in caregiver stressors, social resources, and health: an updated meta-analysis. J Gerontol B Psychol Sci Soc Sci. 2006;61(1):P33-45. https://doi.org/10.1093/ geronb/61.1.p33

38. Abrahams R, Liu KPY, Bissett M, Fahey P, Cheung KSL, Bye R, et al. Effectiveness of interventions for co-residing family caregivers of people with dementia: systematic review and meta-analysis. Aust Occup Ther J. 2018;65(3):208-24. https://doi.org/10.1111/14401630.12464

39. Bank AL, Argüelles S, Rubert M, Eisdorfer C, Czaja SJ. The value of telephone support groups among ethnically diverse caregivers of persons with dementia. Gerontologist. 2006;46(1):134-8. https:// doi.org/10.1093/geront/46.1.134

40. Beauchamp N, Irvine AB, Seeley J, Johnson B. Worksite-based internet multimedia program for family caregivers of persons with dementia. Gerontologist. 2005;45(6):793-801. https://doi. org/10.1093/geront/45.6.793 